\title{
Cerebral aqueduct block attenuates cardio-renal injuries in post-DOCA-NaCl-hypertensive Dahl $\mathrm{R}$ rats
}

\author{
Jong Y Lee and Louis Tobian
}

The systemic and/or local effects of the hydrocephalic brain were investigated in DOCA-NaCl-hypertensive Dahl $\mathrm{R}$ rats induced by $250 \mathrm{mg} \mathrm{kg}^{-1}$ DOCA in silicone and $1 \%$ saline water. After a 1 -week recovery with $0.3 \% \mathrm{NaCl}$ chow and tap water, one group had the aqueduct of Sylvius blocked with silicone and epoxy materials with a control sham group matching mean blood pressure (BP) and body weight. The 4-week-postsurgery $\mathrm{BP}$ on the $0.3 \% \mathrm{NaCl}$ diet averaged $161 \pm 3.2$ in the sham group and $146 \pm 2.3 \mathrm{~mm} \mathrm{Hg}$ in the blocked group $(P<0.0001)$. Both groups were then given an $8 \% \mathrm{NaCl}$ diet and after 4 weeks, the sham group's BP was increased further with markedly increased mortality: $186 \mathrm{~mm} \mathrm{Hg} v$ s. $154 \mathrm{~mm} \mathrm{Hg}(P<0.0001) ; 12$ sham rats died after 11 weeks, while all the blocked rats survived $(P<0.0001)$. A transient change in plasma $\mathrm{Na}$ levels was observed in the blocked group after $48 \mathrm{~h}$ on the $8 \% \mathrm{NaCl}$ diet. At 14 weeks, 0 sham rats survived, compared with 10 out of 16 blocked rats $(P<0.0001)$. After 11 weeks on $8 \% \mathrm{NaCl}$, the average tail venous pressure in the sham group was significantly higher than that of the blocked rats $(P<0.0001)$ indicating the end stage of renal and heart failure. The hearts and kidneys weighed significantly more in the sham vs. the blocked rats $(P<0.0001$ for both groups). These results indicate that the aqueduct block prevents post-DOCA hypertension and cardio-renal injuries, suggesting that centralized third ventricular brain signaling has a role in salt-genetic hypertension.

Hypertension Research (2013) 36, 596-602; doi:10.1038/hr.2013.12; published online 7 March 2013

Keywords: DOCA hypertension; hydrocephalus; $\mathrm{NaCl}$ signal; transient plasma $\mathrm{Na}$; vascular injury

\section{INTRODUCTION}

There is sufficient evidence that the anteroventral third ventricle $(\mathrm{AV} 3 \mathrm{~V})$ area of the brain is a major location of Na-sensitive receptors and is involved in $\mathrm{NaCl}$ hypertension. ${ }^{1-13}$ The $\mathrm{AV} 3 \mathrm{~V}$ is vital for maintaining normal body homeostasis and cardiovascular responses. We need to understand how $\mathrm{NaCl}$ works in raising blood pressure (BP) and the role of the brain's $\mathrm{NaCl}$-control center. Other studies and our results have shown that the AV3V region is a major location of sodium-sensitive receptors and is involved in $\mathrm{NaCl}$-sensitive hypertension. ${ }^{1-9}$ This finding indicates that not only the intact $\mathrm{AV} 3 \mathrm{~V}$, but also the intact cerebroventricular volume space, is required for the $\mathrm{NaCl}$-control center to correctly perceive the $\mathrm{NaCl}$ signal. Central nervous system involvement in the pathogenesis of salt-genetic hypertension is indicated in many other studies. ${ }^{14-16}$ Induced hydrocephalus or AV3V lesion prevents deoxycorticosterone acetate (DOCA) $-\mathrm{NaCl}$ hypertension, creating a model of renin-suppressed, volume-expanded hypertension. ${ }^{5,13}$ If DOCA-NaCl hypertension requires changes in body fluid volumes or sodium balance, the protective effect of the AV3V lesion may result from a disturbance in the necessary changes in fluid or the electrolyte balance. This outcome may result from the influence of a central mechanism of vasopressin (VP) action, which may alter the protection or release of a natriuretic factor. VP may act centrally or on neural target areas, such as paraventricular nuclei (PVN) and supraoptic nuclei, which are involved in cardiovascular regulation. ${ }^{14,15}$ The PVN project sympathetic neurons in the brainstem and spinal cord, and the vagus nuclei regulate the cardiovascular system. ${ }^{14,15}$ Thus, the AV3V region, a major location of the $\mathrm{NaCl}$ receptor center that is involved in Na-dependent hypertension, may be interfering with the VP's neurogenic vasoconstriction activity in DOCA-NaCl hypertension.

In our previous study, we examined mostly BP and mortality in hydrocephalic Dahl S and DOCA-hypertensive Dahl R rats. ${ }^{1-3}$ In the present study, we used post-DOCA Dahl $\mathrm{R}$ rats with an $8 \%$ high $\mathrm{NaCl}$ diet to examine the systemic and local effects of induced hydrocephalus on physiological responses. In addition to effects on $\mathrm{BP}$ and mortality, we examined acute physiological responses to the $8 \% \mathrm{NaCl}$ diet, including water intake and output, plasma $\mathrm{Na}$ levels and $\mathrm{Na}$ excretions, and the long-term effects of venous pressures and cardio-renal responses.

\section{METHODS}

Animals

Three-week-old weanling Dahl-NaCl resistant (Dahl R) male rats were purchased from Harlan Laboratories (Indianapolis, IN, USA) and housed at the university animal facilities with a $12-12$ light-dark cycle. The rats were on a 
regular diet and tap water for 1 week to readjust in this new environment before starting the actual experiment.

\section{DOCA-NaCl treatment}

DOCA-NaCl hypertension was induced in 4-week-old uninephrectomized male Dahl $\mathrm{R}$ rats by subcutaneous $250 \mathrm{mg} \mathrm{kg}^{-1}$ DOCA silicone disk implantation, with regular chow and drinking water containing $1 \% \mathrm{NaCl}$ and $0.2 \% \mathrm{KCl}$. The DOCA disk was removed after 4 weeks, and the rats were switched to $0.3 \% \mathrm{NaCl}$ Purina chow and tap water for a 1-week recovery. The rats were then weighed, and intra-arterial BP was measured under Brevital anesthesia $\left(50 \mathrm{mg} \mathrm{kg}^{-1}\right)$. Using body weights (BWs) and BPs, the post-DOCA rats were divided into two groups with similar mean BWs $(211 \mathrm{~g} v s .219 \mathrm{~g})$ and BPs $(146 \mathrm{~mm} \mathrm{Hg} v s .150 \mathrm{~mm} \mathrm{Hg}$ ).

\section{Aqueductal lesion}

The aqueduct of Sylvius was blocked stereotaxically under pentobarbital anesthesia with a local injection of silicone and epoxy materials, using the method described in our previous studies. ${ }^{1-4}$ After a 1-week recovery from the DOCA treatment with $0.3 \% \mathrm{NaCl}$ chow and tap water, one group had the aqueduct of Sylvius blocked with silicone and epoxy materials, and the other group (with a matching mean BP and BW) had a sham block. The block was confined to the aqueduct. All aqueduct-blocked rats developed a hydrocephalic enlargement of the lateral sides, widening of the slit-like 3V. Sham lesions were performed by making a hole in a region of the skull surface without the cannula entering the brain to ensure that no brain lesions resulted from the cannula itself. The rats were kept on the $0.3 \%$ low $\mathrm{NaCl}$ diet with tap water for an additional 4 weeks, while they were recovering from the DOCA and saline to allow the brains to develop hydrocephalus. Although the swollen condition is not visible, it is possible that the tissue surrounding the $3 \mathrm{~V}$ site tends to become slightly edematous during the $\mathrm{DOCA}-\mathrm{NaCl}$ treatment, causing the ependymal cells and the unmyelinated nerve fibers in the walls of the slit to touch one another when they come into contact with the opposite walls. Widening the slit-like $3 \mathrm{~V}$ by the blocking aqueduct would prevent the walls to touch and reverse the lingering central nervous system effects of DOCA-NaCl. At the end of the study, the brains were fixed using a $10 \%$ neutral formalin solution and dissected to verify the blocked site microscopically, as in our previous study. ${ }^{1}$

\section{Experimental measurements}

At the end of the 4-week recovery period, BW, intra-arterial BP and hematocrit were measured, and both groups of rats began an $8 \% \mathrm{NaCl}$ diet. Blood samples were collected from tail veins after $48 \mathrm{~h}$, and 24 -h urine samples were collected starting at 48 -h post $8 \% \mathrm{NaCl}$ diet through $72 \mathrm{~h}$ on the $8 \% \mathrm{NaCl}$ diet to complete the 24-h urine collection. The baseline and transient plasma $\mathrm{Na}$ and urine $\mathrm{Na}$ values on the high $\mathrm{NaCl}$ diet were compared. After 4 weeks of the high $\mathrm{NaCl}$ diet, intra-arterial BP was measured under Brevital anesthesia $\left(50 \mathrm{~m} \mathrm{~kg}^{-1}\right)$, and hematocrit, plasma Na levels and BW were measured. Tail venous pressure was measured under Brevital anesthesia after 11 weeks on the high $\mathrm{NaCl}$ diet. All of the surgical procedures were conducted in accordance with the National Institutes of Health guidelines and University of Minnesota animal care regulations. Mortality, wet and dry heart and kidney weights were ascertained. The aqueduct blocks were verified histologically using the methods outlined in our previous study. ${ }^{1}$ Pathological examinations were performed for each rat.

\section{Statistics}

The results were analyzed using the least-square method and the two-tailed Student's $t$-test. The data are expressed as mean \pm s.e.m. A $P$-value $<0.05$ was considered to be significant.

\section{RESULTS}

In our present study, aqueduct-blocked Dahl $\mathrm{R}$ rats were used to test acute and long-term systemic and local effects in induced hydrocephalus.

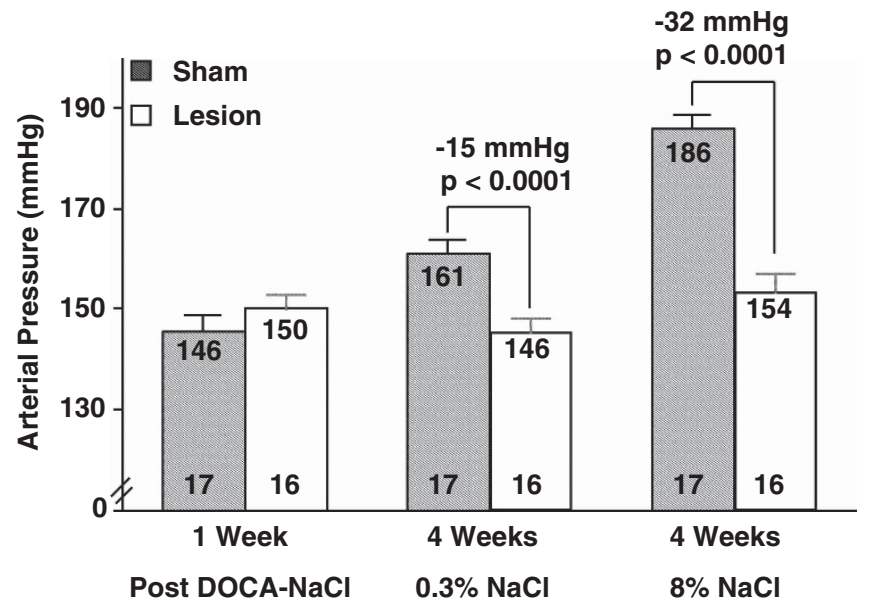

Figure 1 Intra-arterial mean BP $(\mathrm{mm} \mathrm{Hg})$ in post-DOCA $\left(250 \mathrm{mg} \mathrm{kg}^{-1}\right)$ hypertensive Dahl R Rats with either sham or verified aqueductal block. One week post-DOCA, BP was measured, and the rats were divided into sham or aqueduct block groups and matched for BP $(146 \mathrm{~mm} \mathrm{Hg} v s .150 \mathrm{~mm} \mathrm{Hg})$. Sham group was randomly assigned 17 rats and 16 rats were assigned to the blocked group. BP was measured again after 5 weeks post-DOCA, while the rats were still on a $0.3 \%$ low $\mathrm{NaCl}$ diet. After 4 weeks on an $8 \%$ high $\mathrm{NaCl}$ diet, BP was measured again. The mean BPs were significantly attenuated in the blocked group on either the 0.3 or the $8 \% \mathrm{NaCl}$ diet, $P<0.0001$

Figure 1 shows the average arterial BPs at surgery, 4 weeks postsurgery with a $0.3 \%$ low $\mathrm{NaCl}$ diet and 4 weeks post high $\mathrm{NaCl}$ diet. The post-DOCA sham group's average BP was much higher than that of the truly blocked rats, even after 4 weeks on a $0.3 \%$ low $\mathrm{NaCl}$ diet $(161 \pm 3.2 \mathrm{~mm} \mathrm{Hg}$ vs. $146 \pm 2.3 \mathrm{~mm} \mathrm{Hg} ; P<0.0001)$. BPs were further increased in the sham group after 4 weeks.

In Table 1 , water and $\mathrm{NaCl}$ intake values were taken from 24-h volumes after 2 days on the $8 \%$ high $\mathrm{NaCl}$ diet, and the urine volumes were measured from 24-h urine collections starting at $48 \mathrm{~h}$ on the high $\mathrm{NaCl}$ diet. Water intake and urine output interacted significantly in both the sham and truly blocked groups on the $8 \% \mathrm{NaCl}$ diet, but the interaction was significantly greater in the sham rats. Furthermore, a significant water accumulation was observed in the sham group rats after 2 days on the $8 \% \mathrm{NaCl}$ diet $(22.72 \pm 4.95 \mathrm{ml} v$ s. $19.64 \pm 4.54 \mathrm{ml} ; P<0.0001)$. Figure 2 shows plasma sodium levels in the sham and truly blocked groups on a post-DOCA $8 \% \mathrm{NaCl}$ diet. Both the hydrocephalic and sham group rats showed a normal range of plasma $\mathrm{Na}$ concentrations before the high $\mathrm{NaCl}$ diet was introduced $\left(144 \mathrm{mEql}^{-1}\right.$ vs. $\left.141 \mathrm{mEql}^{-1}, P=\mathrm{NS}\right)$. After $48 \mathrm{~h}$ on the $8 \% \mathrm{NaCl}$ diet, the truly blocked group averaged a markedly lower [Na] level compared with the sham group $\left(134.9 \pm 2.4 \mathrm{mEql}^{-1}\right.$ vs. $\left.141.1 \pm 1.9 \mathrm{mEql}^{-1}, P<0.05\right)$. After 4 weeks on the $8 \% \mathrm{NaCl}$ diet, the plasma $\mathrm{Na}$ level of the truly blocked group rats returned to the normal physiological range and become similar to that of the sham group $\left(141 \mathrm{mEql}^{-1}\right.$ vs. $\left.140 \mathrm{mEql}^{-1}, P=\mathrm{NS}\right)$. After $48-72 \mathrm{~h}$ on the $8 \% \mathrm{NaCl}$ diet, the transient urinary $\mathrm{Na}$ excretion of the truly blocked rats averaged $14 \%$ higher than that of the sham group rats, although the difference was not significant $\left(184 \mathrm{mEql}^{-1}\right.$ vs. $210 \mathrm{mEql}{ }^{-1} ; P=$ NS). Of interest was the transient drop in the plasma Na level of the hydrocephalic rats. The truly blocked rats had markedly decreased albuminuria after 3 days on the $8 \% \mathrm{NaCl}$ diet $(181 \mathrm{mg}$ per $24 \mathrm{~h}$ ), while the sham rats averaged $496 \mathrm{mg}$ per $24 \mathrm{~h}(P<0.0001)$; furthermore, there was a significantly higher albumin/creatinine ratio in the sham vs. truly blocked rats (36 vs. $14, P<0.0001)$, indicating that 
Table 1 Transient changes in the aqueductal blocked post-DOCA Dahl $\mathbf{R}$ rats after 2 days on an $8 \% \mathrm{NaCl}$ diet

\begin{tabular}{lcccc}
\hline Surgery & $\begin{array}{c}\text { Water intake } \\
(\mathrm{ml})\end{array}$ & $\begin{array}{c}\mathrm{NaCl} \text { intake } \\
(\mathrm{g})\end{array}$ & $\begin{array}{c}\text { Urine volume } \\
(\mathrm{ml})\end{array}$ & $\begin{array}{c}\text { Water accumulation } \\
(\mathrm{ml})\end{array}$ \\
\hline $\begin{array}{l}\text { Sham } \\
(n=22)\end{array}$ & $96.45 \pm 6.93$ & $1.55 \pm 0.069$ & $73.73 \pm 3.58$ & $22.72 \pm 4.95$ \\
$\begin{array}{l}\text { Blocked } \\
(n=16)\end{array}$ & $75.64 \pm 6.69$ & $1.34 \pm 0.098$ & $55.29 \pm 4.43$ & $19.64 \pm 4.54$ \\
$P$-value & $<0.0001$ & $<0.05$ & $<0.0001$ & $<0.0001$ \\
\hline
\end{tabular}

Abbreviation: $n$, number of rats.

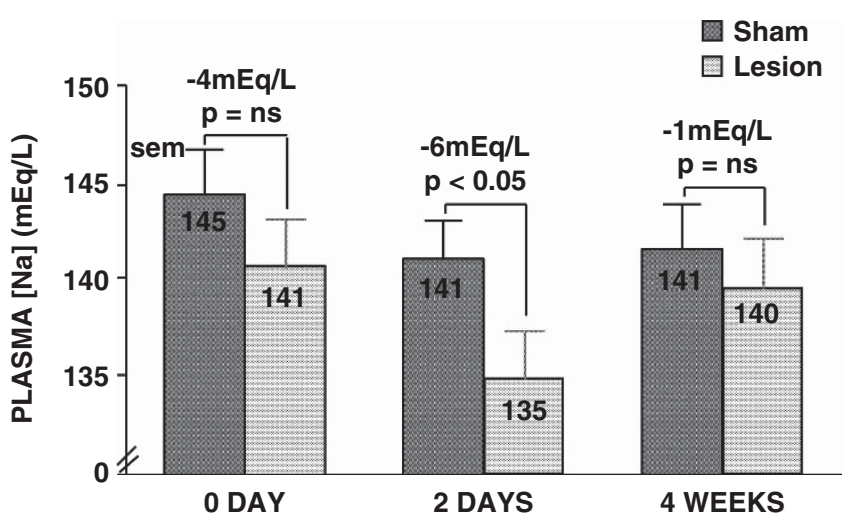

TIME ON 8\% NaCI DIET

Figure 2 Plasma $\mathrm{Na}$ concentration in post-DOCA Dahl $\mathrm{R}$ rats on an 8\% $\mathrm{NaCl}$ diet after the aqueductal block. Before receiving the high $\mathrm{NaCl}$ diet, the two groups had a similar plasma Na concentration $(P=N S)$, though the sham group had a somewhat higher average. However, after 2 days on the high $\mathrm{NaCl}$ diet, the truly blocked group averaged a significantly lower plasma $[\mathrm{Na}$ ] level compared with the sham control group $(P<0.05)$. The plasma $[\mathrm{Na}$ ] level of the blocked group returned to the normal physiological range and became similar to that of the sham group after 4 weeks on the same high $\mathrm{NaCl}$ diet.

kidneys that were already injured by DOCA-NaCl hypertension responded immediately when exposed to the high $\mathrm{NaCl}$ diet among the sham group rats, but were protected in the truly blocked rats.

Venous pressures were measured at the tail veins after 11 weeks on the $8 \% \mathrm{NaCl}$ diet. The sham group had a much higher average venous pressure than the truly blocked group $\operatorname{did}\left(29 \pm 5.9 \mathrm{~mm} \mathrm{H}_{2} \mathrm{O}\right.$ vs. $13 \pm 0.5 \mathrm{~mm} \mathrm{H}_{2} \mathrm{O} ; P<0.0001$, Figure 3). This finding may indicate not only kidney failure but also the end stage of heart failure, with a markedly increased left ventricular end diastole.

Table 2 presents a summary of mortality in post-DOCA-NaClhypertensive Dahl $\mathrm{R}$ rats on an $8 \% \mathrm{NaCl}$ diet after either a sham or a verified aqueductal block. The sham group rats had much higher mortality rates than the truly blocked rats did. After 8 weeks on the $8 \% \mathrm{NaCl}$ diet, 7 of the 17 sham group rats had died, and 12 sham group rats were dead after 11 weeks, while none of the 16 truly blocked rats had died (both $P<0.0001$; a $71 \%$ reduction). All of the sham group rats had died at the end of 14 weeks on the $8 \% \mathrm{NaCl}$ diet, while 10 of the 16 truly blocked rats were still alive $(P<0.0001$; a $65 \%$ reduction). The truly blocked rats showed protection from severe mesenteric arterial lesions, tissue water accumulation, ascites and pleural effusions.

In the heart and kidney weight comparisons, cardiac and renal hypertrophy was prominent in the sham group rats (Table 3 ). The

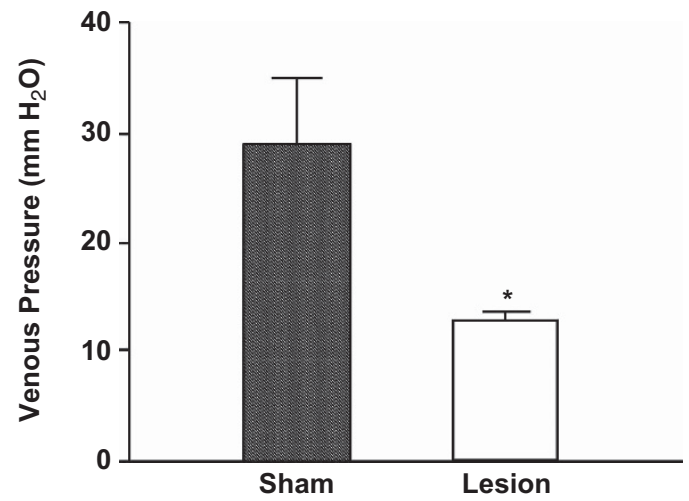

11 Weeks on $8 \% \mathrm{NaCl}$ Diet

Figure 3 Mean venous pressures $\left(\mathrm{mm} \mathrm{H}_{2} \mathrm{O}\right)$ in post-DOCA-hypertensive hydrocephalic Dahl $\mathrm{R}$ rats. Tail venous pressure was measured after 11 weeks on the $8 \%$ high $\mathrm{NaCl}$ diet under Brevital anesthesia. ${ }^{*} P<0.0001$.

Table 2 Significantly low mortality in truly aqueduct-blocked postDOCA Dahl $\mathrm{R}$ rats on an $8 \%$ high $\mathrm{NaCl}$ diet

\begin{tabular}{|c|c|c|c|c|c|}
\hline \multirow{2}{*}{$\begin{array}{l}\text { Post-surgery } \\
8 \% \mathrm{NaCl} \text { (week) }\end{array}$} & \multicolumn{2}{|c|}{ True lesion } & \multicolumn{2}{|c|}{ Sham lesion } & \multirow[b]{2}{*}{ P-value } \\
\hline & Rat alive, $\mathrm{n}$ & Dead, \% & Rat alive, $\mathrm{n}$ & Dead, \% & \\
\hline 1 & 16 & 0 & 17 & 0 & NS \\
\hline 2 & 16 & 0 & 17 & 0 & NS \\
\hline 3 & 16 & 0 & 17 & 0 & NS \\
\hline 4 & 16 & 0 & 17 & 0 & NS \\
\hline 5 & 16 & 0 & 17 & 0 & NS \\
\hline 6 & 16 & 0 & 16 & 1 & NS \\
\hline 7 & 16 & 0 & 16 & 1 & NS \\
\hline 8 & 16 & 0 & 10 & 7 & 0.01 \\
\hline 9 & 16 & 0 & 9 & 8 & 0.005 \\
\hline 10 & 16 & 0 & 7 & 10 & 0.001 \\
\hline 11 & 16 & 0 & 5 & 12 & 0.001 \\
\hline 12 & 14 & 2 & 3 & 14 & 0.001 \\
\hline 13 & 13 & 3 & 3 & 14 & 0.001 \\
\hline 14 & 10 & 6 & 0 & 17 & 0.001 \\
\hline
\end{tabular}

Abbreviations: $n$, number; NS, not significant.

Table 3 Significantly reduced cardiac and renal hypertrophy associated with induced hydrocephalus in post-DOCA Dahl $R$ rats on an $8 \%$ high $\mathrm{NaCl}$ diet

\begin{tabular}{lccc}
\hline Organs (weight, g) & Sham $(\mathrm{n}=17)$ & Block $(\mathrm{n}=16)$ & $\%$ Difference \\
\hline Heart, wet & $2.15 \pm 0.07$ & $1.47 \pm 0.06$ & $-31 \%, P<0.0001$ \\
Dry & $0.46 \pm 0.02$ & $0.30 \pm 0.01$ & $-34 \%, P<0.0001$ \\
Kidney, wet & $2.83 \pm 0.13$ & $2.05 \pm 0.11$ & $-28 \%, P<0.0001$ \\
Dry & $0.56 \pm 0.03$ & $0.43 \pm 0.02$ & $-22 \%, P<0.005$
\end{tabular}

Abbreviation: $n$, number of rats.

sham group had much heavier mean heart weights than the truly blocked group rats did $(2.15 \pm 0.07 \mathrm{~g} v s .1 .47 \pm 0.06 \mathrm{~g}$ for wet hearts and $0.46 \pm 0.02 \mathrm{~g} v$ s. $0.30 \pm 0.01 \mathrm{~g}$ for dry hearts, both $P<0.0001 ; 31 \%$ and $34 \%$ reductions, respectively). The kidney weights of the sham group averaged $2.83 \pm 0.13 \mathrm{~g}$, while the truly blocked rats had 
significantly reduced wet weight $(2.05 \pm 0.11 \mathrm{~g} ; P<0.0001)$ and dry weight reductions of $0.56 \pm 0.03$ vs. $0.43 \pm 0.02(P<0.005 ; 28 \%$ and $22 \%$ reductions, respectively).

Overt nephrotic syndrome was observed in all of the sham group rats, which had severe ascites, pleural effusions and the edematous body, while these features were absent or considerably delayed in the truly blocked rats.

\section{DISCUSSION}

Our results indicate that the aqueduct block partially prevents postDOCA hypertension and heart and kidney injuries via centralized third ventricular brain signaling in salt-genetic hypertension. Although a high $\mathrm{NaCl}$ diet is a well-known causal factor in increased $\mathrm{BP}$, which leads to cardiovascular disease and chronic kidney disease, understanding the relationship between high dietary $\mathrm{NaCl}$ intake and increased BP is more complicated than we can recognize. The AV3V is vital for maintaining normal body homeostasis and cardiovascular responses. However, we still do not understand the $\mathrm{NaCl}$ mechanisms in raising $\mathrm{BP}$ and the role of the brain's $\mathrm{NaCl}$-control center. Our previous studies of Sprague Dawley (SD) and Dahl rats showed markedly attenuated BP and mortality resulting from induced hydrocephalus, ${ }^{1-4}$ but we did not find similar results in a large number of stroke-prone spontaneously hypertensive rats. Dahl S and $\mathrm{R}$ rat strains derived from the $\mathrm{SD}$ rat strain; thus, they may share some genetic components involved in centralized $\mathrm{NaCl}$ signaling concepts, which may be linked to $\mathrm{NaCl}$ hypertension.

High-salt intake is a major cause of elevated BP, coronary heart disease, increased risk of stroke, left ventricular hypertrophy and renal disease. ${ }^{17-19}$ Studies suggest that hypothalamic regulatory centers are the sites of the activities of mineralocorticoids (MC), which have major effects on salt appetite, thirst and $\mathrm{BP}^{8,20,21}$ These studies report that DOCA administration in rats resulted in an increased salt appetite, which rapidly reverted to a control level after the end of the DOCA treatment. The changes in DOCA treatment were expressed as the parallel effects of the MC in the hypothalamic regulatory centers for salt appetite, thirst and BP. The activities of the regulatory centers change in response to increased intracellular sodium content with increased membrane permeability of the MC at the cellular level of the regulatory centers. The central action of DOCA was suggested because standard treatment with MC does not induce hypertension, but the same concentration administered into the lateral cerebral ventricle causes hypertension.

In other studies, intraventricular infusion of hypertonic $\mathrm{NaCl}$ with DOCA administration induced MC hypertension. The central action of $\mathrm{NaCl}$ resulted in an alteration in enhanced vascular responsiveness to norepinephrine, serotonin and angiotensin II (AII), especially in the mesenteric arteries. ${ }^{22,23}$ A pressor effect produced by the intracerebroventricular VP injection resulted in the activation of the sympathetic nervous system, but this effect resulted in a decreased urinary excretion rate. ${ }^{24-27}$ Subsequent studies by other investigators confirmed that intracerebroventricular injection of MC antagonist blocks the hypertension induced by aldosterone ${ }^{28,29}$ and by DOCA. ${ }^{30}$ The same dose of the antagonist does not greatly affect BP when given locally through intraperitoneal or subcutaneous injection. The intracerebroventricular infusion of aldosterone also causes a 100fold more potent hypertensinogenic, which showed neither polydipsia nor polyuria (as seen in saline polydipsia evidenced by polyuria) compared with subcutaneous administration. This result may indicate that the BP regulatory center differs from the thirst regulatory center. However, the center may be identical to central catecholaminergic effector centers, as evidenced by 6-hydroxydopamine or diltiazem blocks that reverse DOCA-NaCl hypertension, while intravenous injections do not. ${ }^{28-32}$ A combination of sympathectomy, using 6hydroxydopamine and by bilateral adrenalectomy, resulted in a rapid and marked drop in BP in both normotensive and hypertensive animals, but chemical sympathectomy or adrenalectomy alone reduced BP only slightly. ${ }^{33,34}$ This result indicates that DOCA and $\mathrm{NaCl}$ may be involved in a synergic hyperactivity of the sympathetic fibers and adrenal medulla.

The rostroventrolateral medulla (RVLM) in the brainstem is a key site for the regulation of vasomotor tone. Sympathoexcitatory neurons project from this region to contact sympathetic preganglionic neurons located in the thoracic-lumbar spinal cord. These neurons are organized for the selective and differential control of autonomic effectors and are particularly involved in cardiovascular regulation. ${ }^{35}$ When PVN is stimulated, VP, a spinal neurotransmitter released in the PVN, consistently increases the amplitude of renal sympathetic nerve activity, arterial pressure and the peak-to-peak interval of discharges, while VP antagonists block the hemodynamic response to PVN stimulation, ${ }^{14-16,36}$ as AII injected intrathecally increases BP and sympathetic activity and an AII antagonist prevents the changes. ${ }^{37}$ Bilateral lesions of the PVN and the AV3V reduced NaCl-related hypertension with the many damaged catecholamine-containing neurons in the electrically destroyed regions. ${ }^{5,6,9,10}$ We would not expect the same mechanism to be involved in BP reductions with intact cells and nerve fibers in the hydrocephalic $3 \mathrm{~V}$ regions. Other studies suggest that phenylethanolamine- $N$-methyltransferase (C1 neurons) from the RVLM are involved in regulating sympathetic outflow and BP, maintaining cardiovascular responses and resting BP in anesthetized rats. ${ }^{38}$ The afterdepolarization potential in presympathetic PVN neurons with greater depolarizing input resistance likely contributes to the increased excitability of the PVNRVLM neurons with AII-salt hypertension. ${ }^{39}$ The depletion of $84 \%$ of bulbospinal $\mathrm{C} 1$ adrenergic neurons did not alter RVLM sympathetic nerve activity and resting BP but this depletion reduced heart rates in anaesthetized rats, while lowering BP with similar heart rates in conscious rats. The loss of $\mathrm{C} 1$ neurons reduces sympathoexcitatory and pressor responses, suggesting that $\mathrm{C} 1$ cells are critical for the full expression of sympathoexcitatory responses generated by the RVLM. $^{40,41}$ Somatostatin $2 \mathrm{~A}$ receptors in RVLM presympathetic neurons also appear to maintain resting $\mathrm{BP}$, as evidenced by the ability of somatostatin and receptor-agonists to evoke dramatic hypotension and bradycardia. ${ }^{42}$

The activation of PVN neurons in the hypothalamus produced sympathetic nerve activity accompanying a pressor response in decreased renal sympathetic activity, together with an increase in splanchnic, adrenal and cardiac sympathetic activity mediated by gamma-aminobutyric acid, indicate that PVN can be functionally significant in the cardiovascular response induced by blood volume expansion. ${ }^{43}$ Intravenous phenylephrine-induced baroreceptor stimulation significantly reduced spinally evoked responses, while glycine injections to the ventral surface of the medulla produced a profound hypotension, during which sympathetic vasoconstrictor activity in splanchnic, renal and skeletal muscle vascular beds was reduced with gamma-aminobutyric acid synapses in the spinal sympathetic circuits. ${ }^{44}$

Normal pressure hydrocephalus (NPH) is the most frequent form of chronic hydrocephalus in adults, but the pathogenesis of idiopathic $\mathrm{NPH}$ is unknown. ${ }^{45,46}$ Hydrocephalus is caused by an obstruction to the flow of cerebrospinal fluid (CSF), however, a small pressure gradient obstruction to CSF flow is sufficient to overcome the added resistance to flow and thereby balance the absorption of CSF with its 
production. ${ }^{47}$ Enlarged basal cisterns and sylvian fissures and focally dilated sulci support the diagnosis of shunt-responsive idiopathic $\mathrm{NPH}$, a condition caused by a suprasylvian subarachnoid block. ${ }^{48}$ In addition, astrogliosis was significantly higher in NPH patients compared with neurologically healthy age-matched controls. ${ }^{49}$ Aqueduct CSF stroke volume and peak systolic and diastolic velocity values in the aqueduct of Sylvius were significantly higher in patients with hydrocephalus before shunt surgery and became similar to those of the control group after the shunting surgery. ${ }^{50}$ Increased intracranial pressure might stimulate VP release in the CSF and for plasma VP concentrations that are inappropriate to the corresponding plasma osmolality. ${ }^{51}$ Despite increased intracranial pressure in hydrocephalic brains, normal BP is maintained in most elderly patients and animals in chronic hydrocephalus. ${ }^{52-56}$

In our current study, the cerebral aqueduct was discretely blocked stereotaxically to produce hydrocephalus. Rats in both groups maintained normal drinking responses and urine excretion. However, the truly blocked rats showed significantly lower amounts of water intake $(75.6 \pm 6.7 \mathrm{ml}$ per $24 \mathrm{~h})$ and urine excretion $(55.3 \pm 4.4 \mathrm{ml}$ per $24 \mathrm{~h})$ compared with the sham group rats $(96.5 \pm 6.9 \mathrm{ml}$ per $24 \mathrm{~h}$ for water intake, $P<0.005$, and $73.7 \pm 3.6 \mathrm{ml}$ per $24 \mathrm{~h}$ for urine excretion, $P<0.0001)$. The average $\mathrm{NaCl}$ intake in the sham rats was also higher than that in the truly blocked group $(1.55 \mathrm{~g}$ vs. $1.34 \mathrm{~g}$ per $24 \mathrm{~h}$; $P<0.05)$. Despite the higher water intake and output of the sham group rats, the average urinary $\mathrm{Na}$ excretion was $14 \%$ higher in the blocked rats $\left(210.3 \mathrm{mEql}^{-1}\right.$ vs. $\left.184.2 \mathrm{mEql}^{-1}\right)$.

The average BWs in both groups were similar until toward the end stage of hypertension, in which the sham group rats averaged a $6 \%$ lower weight than the blocked rats. The transient drop in the plasma $\mathrm{Na}$ of the truly blocked group (Figure 2) may be influenced by differences in the intake and output of $\mathrm{NaCl}$ and water balance or by the central trigger mechanism. Water intake and urinary output interacted significantly $48 \mathrm{~h}$ postsurgery among rats on the $8 \% \mathrm{NaCl}$ diet in both the sham and truly blocked groups, but the interaction was significantly greater with a significant water accumulation in the sham group rats following 2 days on the $8 \% \mathrm{NaCl}$ diet.

The observations in our and other studies may explain some physiological changes via central and local mechanisms. These acute physiological responses to immediately following the $8 \%$ high $\mathrm{NaCl}$ diet may be very important features involved in $\mathrm{NaCl}$ hypertension. For longer-term effects, we observed that the sham group rats manifested overt nephrotic syndromes, including entire body edema with severe ascites, markedly increased albuminuria (495.71 mg per $24 \mathrm{~h}$ in the sham group $v s .181 .38 \mathrm{mg}$ per $24 \mathrm{~h}$ in the truly blocked group) and massive pleural effusions, and the sham rats died of renal and respiratory failures. These results indicate that kidneys injured by acute DOCA-NaCl hypertension experienced continuing injury that extended to the hearts of the sham blocked rats, while the kidneys of truly blocked rats appeared to be protected from further injury. Truly blocked rats showed protection from severe mesenteric arterial lesions, the leading cause of death in the sham group. It appears that the aqueduct block reduces the post-DOCA-NaCl signal, thereby protecting against post-DOCA hypertension and preventing the vessel injuries of post-DOCA hypertension. We assume that the truly blocked aqueduct reduces hypertensive injuries, perhaps via lowered BP and reduced arterial lesions. However, a recent study suggested that albuminuria was as severe in hypertensives after BP was reduced and kidney vessel pathology was prevented with enalapril treatment. ${ }^{57}$

Cardio-renal hypertrophy was prominent in our sham rats. Hypertensive cardiac hypertrophy does not appear to be simply a response to the mechanical stress of increased afterload. Many neural and hormonal stimuli have been proposed in cardiac muscle growth, including adrenergic agonists. Studies have demonstrated that other factors, such as sympathetic activity, might be more important to the degree of cardiac hypertrophy. ${ }^{58} \mathrm{High} \mathrm{NaCl}$ is known to increase sympathetic activity by modifying a release of neurotransmitters and causing changes in $\beta$-adrenergic receptors, which can influence cardiac hypertrophy. This finding suggests the possible involvement of the sympathetic nervous system in accelerated cardiac hypertrophy, as observed in our sham-lesioned rats.

Studies indicate that high $\mathrm{NaCl}$ affects renal growth differently in salt-sensitive and -insensitive rat strains. Renal hyperplasia was much more prominent, and renal hypertrophy was greatly increased, with longer $\mathrm{NaCl}$ feeding in salt-sensitive strains compared with salt-insensitive strains. ${ }^{59}$ Increased kidney weights may be caused by renal hyperplasia and cell hypertrophy that existed before the introduction of a high $\mathrm{NaCl}$ diet, or they may result from the compensatory hypertrophy of nephrons. Water and cast accumulation in the tissues may also contribute to the heavier kidney weights in our sham group rats. We kept the AV3V region intact but disturbed the intraventricular space by inducing hydrocephalus to test how the salt-volume center perceives the $\mathrm{Na}$ signal. We again found attenuated BP and mortality in post-DOCA Dahl $\mathrm{R}$ rats, together with acute changes in intake-output and transient plasma $\mathrm{Na}$ and long-term effects on venous pressure and cardio-renal protection in hydrocephalic brains. The aqueductal block lowered BP even when the rats were fed $0.3 \% \mathrm{NaCl}$ chaw as compared with the sham group rats. We also observed mesenteric vascular lesions in many rats in the sham group. However, the phenomena were different from that of Dahl S rats with severe vascular pathological changes without chronic blood loss through the mesenteric arteries. In our Dahl S rat study, many sham group rats had chronic blood loss in the chronic blood clotting process. Sudden cerebral hemorrhaging was not observed in the Dahl R rats as often as in the high $\mathrm{NaCl}$-fed sham-blocked Dahl $\mathrm{S}$ rats.

In summary, DOCA- $\mathrm{NaCl}$ induces hypertension that causes arterial lesions (especially in cerebral and mesenteric arteries) and organic cellular damage, thus, increasing BP and mortality, while the arterial and local organ lesions are markedly reduced in hydrocephalic DOCA Dahl R rats, similar results seen in our Dahl S rat study. The excessive extracellular fluid volume caused by a high $\mathrm{NaCl}$ diet may swell the local tissue at the sites of the slit-like $3 \mathrm{~V}$, which could cause the ependymal cells and nerve fibers to touch one another. This contact could trigger neural/humoral signals, resulting in hypertension in susceptible individuals and vascular injuries that lead to increased mortality. Our results indicate that the aqueduct block prevents post-DOCA hypertension and heart and kidney injuries. However, BP was partially reduced in the truly blocked groups, indicating that some other mechanisms may also be involved in saltgenetic hypertension. Unfortunately, we did not measure the potential neurotransmitters that would be involved in this study.

Significant BP reduction can be achieved by a public campaign to reduce dietary salt intake to prevent the salt-induced lesions that lead to cardiovascular disease and chronic kidney disease morbidity and mortality, as no genetic test for salt sensitivity is readily available. A meta-analysis result has suggested that systolic BP was reduced $\sim 1 \mathrm{mmHg}$ with every $1 \mathrm{~g}$ per day decrease in salt intake in hypertensive subjects. ${ }^{60}$ In our earlier studies, moderate increases in perinatal dietary salt predisposed offspring's salt sensitivity and resulted in adverse effects later in life, when a high-salt was reintroduced. ${ }^{61}$ This outcome indicates that epigenetic effects also have a significant role in $\mathrm{NaCl}$-induced hypertension. 


\section{FUTURE STUDY DIRECTIONS}

$\mathrm{NaCl}$ hypertension is involved in various aspects of genetics, which are significantly influenced by environmental factors. Future study designs should include the main factors potentially involved in the centralized signaling concepts in $\mathrm{NaCl}$ hypertension, including catecholamines and possible epigenetic and environmental factors.

\section{CONFLICT OF INTEREST}

The authors declare no conflict of interest.

\section{ACKNOWLEDGEMENTS}

The author thanks Dr Franz Halberg for his invaluable advice and comments, Dr Charles Christians for his review of the manuscript, and Mr John S Lee for his editorial assistance and reviews. This work was supported by National Institutes of Health grant RO1 HL-17871, The Cargill Foundation and a grant from the Minnesota Medical Foundation, Minneapolis, Minnesota. This work is dedicated to Dr Louis Tobian, who became ill and could not see it published before his passing.

1 Lee JY, Tobian L, Hanlon S, Hamer R, Johnson MA, Iwai J. How is the $\mathrm{NaCl}$ signal transmitted in $\mathrm{NaCl}$-induced hypertension? Hypertension 1989; 13: 668-675.

2 Lee JY, Tobian L. Aqueduct block markedly reduces mortality rate, BP, cardiac hypertrophy and albuminuria in post-DOCA Dahl R rats. Hypertension 1991; 17: 1197-1203.

3 Lee JY. Protective effects in ambulatory blood pressure and centralized injuries in hydrocephalic Dahl rats on high and low $\mathrm{NaCl}$ diets. Am J Hypertens 2003; 16: 307-311.

4 Lee JY, Tobian L. Effects of induced third brain ventricular hydrocephalus in DOCA$\mathrm{NaCl}$ hypertensive Sprague Dawley rats. World Heart J 2012 (in press).

5 Berecek KH, Barron KW, Webb RL, Brody MJ. Vasopressin-central nervous system interactions in the development of DOCA hypertension. Hypertension 1982; 4 (suppl II), II-131-II-137.

6 Goto A, Ganguli M, Tobian L, Johnson MA, Iwai J. Effect of an anteroventral third ventricle lesion on $\mathrm{NaCl}$ hypertension in Dahl salt-sensitive rats. Am J Physiol 1982; 243: $\mathrm{H} 614-\mathrm{H} 618$.

7 Genest J. Progress in hypertension research: 1900-2000. Hypertension 2001; 38: E13-E18.

8 Rahmouni K, Barthelmebs M, Grima M, Imbs JL, De Jong W. Involvement of brain mineralocorticoid receptor in salt-enhanced hypertension in spontaneously hypertensive rats. Hypertension 2001; 38: 902-906.

9 Songu-Mize E, Bealer SL, Caldwell RW. Effect of AV3V lesion on development of DOCA-salt hypertension and vascular $\mathrm{Na}+$-pump activity. Hypertension 1982; 4: 575-580.

10 Berecek KH, Barron KW, Webb RL, Brody MJ. Relationship between vasopressin and the anteroventral third ventricle region in deoxycorticosterone/salt hypertension. Ann NY Acad Sci 1982; 394: 392-397.

11 Songu-Mize E, Bealer SL, Caldwell RW. Effect of DOCA-salt treatment duration and anteroventral third ventricle lesions on a plasma-borne sodium pump inhibitor in rats. J Hypertens 1987; 5: 461-467.

12 Sanders BJ, Johnson AK. Lesions of anteroventral third ventricle prevent salt-induced hypertension in the borderline hypertensive rat. Hypertension 1989; 14: 619-622.

13 Brody MJ, Fink GD, Buggy J, Haywood JR, Gordon FJ, Johnson AK. The role of anteroventral third ventricle (AV3V) region in experimental hypertension. Circ Res 1978; 43 (suppl I), I-2-I-13.

14 Goto A, Ikeda T, Tobian L, Iwai J, Johnson MA. Brain lesions in the paraventricular nuclei and catecholaminergic neurons minimize salt hypertension in Dahl salt-sensitive rats. Clin Sci 1981; 61: 53S-55S

15 Nakata T, Takeda K, Itho H, Hirata M, Kawasaki S, Hayashi J, Oguro M, Sasaki S, Nakagawa M. Paraventricular nucleus lesions attenuate the development of hypertension in DOCA/salt-treated rats. Am J Hypertens 1989; 2: 625-630.

16 Brody MJ, Barron KW, Berecek KH, Faber JE, Lappe RW. Neurogenic mechanisms of experimental hypertension. In: Genest J, Kuchel O, Hamet P and Cantin M (eds) Hypertension: $2^{\text {nd }}$ edn, pp 117-140 (McGraw-Hill Book Co, New York, USA, \& 17 other cities worldwide, 1983).

17 Mohan S, Campbell NR. Salt and high blood pressure. Clin Sci 2009; 117: 1-11.

$18 \mathrm{He}$ FJ, Jenner KH, Macgregor GA. WASH-world action on salt and health. Kidney Int 2010; 78: 745-753.

19 He FJ, Burnier M, Macgregor GA. Nutrition in cardiovascular disease: salt in hypertension and heart failure. Eur Heart J 2011; 32: 3073-3080.

$20 \mathrm{Gomez}-\mathrm{Sanchez}$ EP. Intracerebroventricular infusion of aldosterone induced hypertension in rats. Endocrinol 1986; 118: 819-823.

21 Hamlin MN, Webb RC, Ling WD, Bohr DF. Parallel effects of DOCA on salt appetite, thirst, and BP in sheep. Proc Soc Exp Biol Med 1988; 188: 46-51.
22 Soltis EE, Bohr DF. Central action of sodium chloride on BP and vascular responsiveness in the rat. Hypertension 1986; 8 (suppl I), I-52-I-55.

23 Soltis EE, Bohr DF. Central action of sodium chloride on whole body pressure responsiveness in the DOCA-treated rat. J Hypertens 1989; 7: 383-386.

24 Pittman QJ, Lawrence D, McLean L. Central effect of arginine vasopressin on BP in rats. Endocrinol 1982; 110: 1058-1060.

25 Janiak P, Kassan BG, Brody MJ. Central vasopressin raise arterial pressure by sympathetic activation and vasopessin release. Hypertension 1989; 13: 935-940.

26 Rohmeiss P, Becker H, Dietrich R, Luft F, Unger T. Vasopressin: mechanism of central cardiovascular action in conscious rats. J Cardiovasc Pharmacol 1986; 8: 689-696.

27 Janiak P, Brody MJ. Central interactions between aldosterone and vasopressin on cardiovascular system. Am J Physiol 1988; 255: R166-R173.

28 Gomez-Sanchez EP. Dose-response studies of intracerebro-ventricular infusion of aldosterone in sensitized and nonsensitized rats. J Hypertens 1988; 6: 437-442.

29 Gomez-Sanchez EP, Fort CM, Gomez-Sanchez CE. Intracerebroventricular infusion of RU28318 blocks aldosterone-salt hypertension. Am J Physiol 1990; 258: E482-E484.

30 Janiak P, Brody MJ. Role of central mineralocorticoids(MC) binding sites (BS) in the development of DOCA-salt hypertension (DCO-H) in the rat. FASEB 1988; 2: 5719. Abs.

31 Haeusler G, Finch L, Thoenen H. Central adrenergic neurons and the initiation and development of experimental hypertension. Experientia 1972; 28: 1200-1203.

32 Takahashi H, Okabayashi H, Suga K, Iyoda I, Matsuzawa M, Ikegaki I, Yoshimura M, Ijichi $\mathrm{H}$. Augmented vasodepressor and sympathetic responses to intracerebroventricular injection of diltiazem, a calcium channel blocker, in DOCA-salt hypertensive rats. J Hypertens 1986; 4 (suppl 6), S156-S159.

33 de Champlain J, van Ameringen MR. Regulation of BP by sympathetic nerve fibers and adrenal medulla in normotensive and hypertensive rats. Circ Res 1972; 31: 617-628.

34 Mueller RA, Thoenen H, Axelrod J. Adrenal tyrosine hydroxylase; compensatory increase in activity after chemical sympathectomy. Science 1967; 163: 468-469.

35 Pyner S, Coote JH. Rostroventrolateral medulla neurons preferentially project to targetspecified sympathetic preganglionic neurons. Neuroscience 1998; 83: 617-631.

36 Malpas SC, Coote JH. Role of vasopressin in sympathetic response to paraventricular nucleus stimulation in anesthetized rats. Am J Physiol 1994; 266 (1 Pt 2), R228-R236.

37 Suter C, Coote JH. Intrathecally administered angiotensin II increases sympathetic activity in the rat. Auton Nerv Syst 1987; 19: 31-37.

38 Madden CJ, Sved AF. Rostral ventrolateral medulla C1 neurons and cardiovascular regulation. Cell Mol Neurobiol 2003; 23: 739-749.

39 Guyenet PG, Schreihofer AM, Stornetta RL. Regulation of sympathetic tone and arterial pressure by the rostral ventrolateral medulla after depletion of $\mathrm{C} 1$ cells in rats. Ann NY Acad Sci 2001; 940: 259-269.

40 Schreihofer AM, Stornetta RL, Guyenet PG. Regulation of sympathetic tone and arterial pressure by rostral ventrolateral medulla after depletion of $\mathrm{C} 1$ cells in rat. J Physiol 2000; 529 (Pt 1), 221-236.

41 Madden CJ, Sved AF. Cardiovascular regulation after destruction of the C1 cell group of the rostral ventrolateral medulla in rats. Am J Physiol Heart Circ Physiol 2003; 285: H2734-H2748.

42 Burke PG, Li Q, Costin ML, McMullan S, Pilowsky PM, Goodchild AK. Somatostatin 2A receptor-expressing presympathetic neurons in the rostral ventrolateral medulla maintain blood pressure. Hypertension 2008; 52: 1127-1133.

43 Deering J, Coote JH. Paraventricular neurones elicit a volume expansion-like change of activity in sympathetic nerves to the heart and kidney in the rabbit. Exp Physiol 2000; 85: 177-186.

44 Lewis DI, Coote JH. Baroreceptor-induced inhibition of sympathetic neurons by GABA acting at a spinal site. Am J Physiol 1996; 270 (Pt 2), H1885-H1892.

45 Kondziella D, Sonnewald U, Tullberg M, Wikkelso C. Brain metabolism in adult chronic hydrocephalus. J Neurochem 2008; 106: 1515-1524.

46 Li X, Miyajima M, Mineki R, Taka H, Murayama K, Arai H. Analysis of potential diagnostic biomarkers in cerebrospinal fluid of idiopathic normal pressure hydrocephalus by proteomics. Acta Neurochir 2006; 148: 859-864.

47 Levine DN. Intracranial pressure and ventricular expansion in hydrocephalus: have we been asking the wrong question? J Neurol Sci 2008; 269: 1-11.

48 Kitagaki H, Mori E, Ishii K, Yamaji S, Hirono N, Imamura T. CSF spaces in idiopathic normal pressure hydrocephalus: morphology and volumetry. Am J Neuroradiol 1998. 19: $1277-1284$

49 Tullberg M, Rosengren L, Blomsterwall E, Karlsson JE, Wikkelsö C. CSF neurofilament and glial fibrillary acidic protein in normal pressure hydrocephalus. Neurology 1998; 50: 1122-1127.

50 Abbey P, Singh P, Khandelwal N, Mukherjee KK. Shunt surgery effects on cerebrospinal fluid flow across the aqueduct of Sylvius in patients with communicating hydrocephalus. J Clin Neurosci 2009; 16: 514-518.

51 Sørensen PS, Gjerris F, Hammer M. Cerebrospinal fluid vasopressin and increased intracranial pressure. Ann Neurol 1984; 15: 435-440.

52 Vanneste J, Hyman R. Non-tumoral aqueduct stenosis and normal pressure hydrocephalus in elderly. J Neurol Neurosurg Psychiatry 1986; 49: 529-535.

53 Rosenberg GA, Saland L, Kyner WT. Pathophysiology of periventricular tissue changes with raised CSF pressure in cats. J Neurosurg 1983; 59: 606-611.

54 Higashi K, Hiroshi A, Ueda N, Kobayashi K, Hara K, Noda Y. Cerebral blood flow and metabolism in experimental hydrocephalus. Neurol Res 1986; 8: 169-176.

55 Hashimoto M, Ishikawa M, Mori E, Kuwana N. Diagnosis of idiopathic normal pressure hydrocephalus is supported by MRI-based scheme: a prospective cohort study. Cerebrospinal Fluid Res 2010; 7: 18-29. 
56 Stephensen $\mathrm{H}$, Tisell $\mathrm{M}$, Wikkelsö $\mathrm{C}$. There is no transmmantle pressure gradient in communicating or noncommunicating hydrocephalus. Neurosurgery 2002; 50: 763-771.

57 Feld LG, Cachero S, Van Liew JB, Zamlauski-Tucker M, Noble B. Enalapril and renal injury in spontaneously hypertensive rats. Hypertension 1990; 16: 544-554.

58 Lindpaintner K, Sen S. Role of sodium in hypertensive cardiac hypertrophy. Cir Res 1985; 57: 610-617.

59 McCormick CP, Rauch AL, Buckalew VM Jr. Differential effect of dietary salt on renal growth in Dahl salt-sensitive and salt-resistant rats. Hypertension 1989; 13: 122-127.
60 Kawano Y, Ando K, Matsuura H, Tsuchihashi T, Fujita T, Ueshima HWorking Group for Dietary Salt Reduction of the Japanese Society of Hypertension. Report of the working group for Dietary Salt Reduction of the Japanese Society of Hypertension: (1) rationale for salt restriction and salt-restriction target level for the management of hypertension. Hypertens Res 2007; 30: 879-886.

61 Lee JY, Azar SH. Wistar-Kyoto and spontaneously hypertensive rat blood pressure after embryo transfer into different wombs and cross-suckling. Exp Biol Med 2010; 235 $1-10$. 